\title{
Um olhar crítico sobre os projetos terapêuticos singulares
}

\author{
Fernando Sfair Kinker \\ Departamento Saúde, Clínica e Instituições, Universidade Federal de São Paulo - UNIFESP, Santos, SP, Brasil.
}

\begin{abstract}
Resumo: Este artigo problematiza a questão dos projetos terapêuticos singulares no âmbito dos serviços de saúde mental construídos no processo de reforma psiquiátrica brasileira. Partindo das concepções que foram ganhando força tanto no campo da reforma psiquiátrica como no da saúde coletiva, problematiza que a noção de projeto terapêutico ainda sofre influências de paradigmas biológicos, psicológicos ou sociais que simplificam a complexidade da experiência dos sujeitos que sofrem. Apesar de os projetos terapêuticos representarem uma conquista fundamental para a qualificação do cuidado em saúde mental, ainda se faz necessário produzir uma ruptura epistemológica na relação com o sofrimento psíquico, para que eles possam atingir maior potencial de transformação. Desta forma, $\mathrm{o}$ artigo propõe que a prática dos projetos terapêuticos dialogue com a realidade concreta de vida dos usuários e suas relações nos territórios de existência, de forma a transformar as relações de poder e de saber que reproduzem a anulação dos sujeitos. Agindo desta forma, é possível dialogar com a complexidade da experiência do sofrimento psíquico, produzindo transformações nas cenas que o produzem.
\end{abstract}

Palavras-chave: Atenção à Saúde, Serviços de Saúde Mental, Reforma Psiquiátrica.

\section{A critical view on singular therapeutic projects}

Abstract: This article discusses the issue of singular therapeutic projects within the mental health services built in
the Brazilian psychiatric reform process. Starting from the concepts that have gained strength in both the psychiatric
reform as in the collective health, this study proposes that current notions of therapeutic project still are influenced
by biological, psychological or social paradigms that simplify the complexity of the experience suffered by the
subjects. Despite therapeutic projects are an essential achievement for the qualification of mental health care, it is
still necessary to produce a epistemological rupture in the relationship with mental suffering, so that they can achieve
the greatest potential for transformation. Therefore, the article suggests that the practice of therapeutic projects
should hold discussions with the reality of users life of and their relationships in the territories of existence, in order
to transform the relations of power and knowledge that reproduce the subjects annulment. Thus, it is possible to
dialogue with the complexity of the mental suffering experience, producing changes in the scenes that produces it.

Keywords: Health Care, Mental Health Services, Psychiatric Reform. 


\section{Introdução}

A proposta deste artigo é problematizar um dos conceitos balizadores do cotidiano dos serviços de saúde mental construídos no processo brasileiro de reforma psiquiátrica. Trata-se do conceito de Projeto Terapêutico Singular, ou Projeto Terapêutico individual.

As reflexôes apresentadas aqui têm como referência a experiência de supervisão clínico-institucional em vários CAPS do Estado de São Paulo durante a década de 2000, as discussóes no campo da graduação junto aos alunos do curso de terapia ocupacional da UNIFESP, as reflexôes com alunos e docentes dos vários cursos de graduação da UNIFESP - baixada santista e profissionais da rede em torno do Laboratório de Produção de Conhecimento Compartilhado em Saúde Mental, e os diálogos realizados em grupos de pesquisa da universidade. Contribuíram também para estas reflexôes a participaçáo do pesquisador em estudo coordenado por colegas docentes da UNICAMP e da UNIFESP em 2011, com o objetivo de construir de forma participativa indicadores de avaliação dos CAPS III do Estado de São Paulo.

Sendo assim, o artigo não se pautará no relato de uma experiência singular, mas trará reflexôes que têm como base a vivência do autor em vários serviços territoriais ao longo dos últimos anos.

\section{Genealogia dos Projetos terapêuticos}

A questão dos projetos terapêuticos surge no contexto da reforma psiquiátrica com a implantação dos primeiros serviços territoriais e comunitários.

A experiência de desconstruçáo do hospital psiquiátrico de Santos e sua simultânea substituição por serviços comunitários e territoriais durante os anos 1990, que influenciaram experiências singulares que seguiram pressupostos semelhantes como as de Campinas, Belo Horizonte, dentre outras, representaram momentos de experimentação e construção de projetos terapêuticos focados na 'existência-sofrimento em sua relação com o corpo social' (ROTELLI, 1990), implicando um criativo e tenso diálogo com a realidade concreta de vida dos usuários e os atores envolvidos nesses territórios existenciais (NICÁCIO, 1994). A contínua multiplicação de experiências sociais e de formas de diálogo envolvia movimentos de mudança nos contextos em que a vida se dava, nos valores, nas condições materiais e relacionais de vida, exigindo novas práticas e saberes. Eis porque aqui os projetos terapêuticos podiam ser compreendidos como projetos de vida (NICÁCIO, 2003) que se teciam numa rede mútua de interaçóes, multiplicando e modificando as redes de dependência, produzindo autonomia (KINOSHITA, 1996).

Posteriormente, a discussão sobre os projetos terapêuticos começou a assumir uma importância maior no campo da saúde coletiva (CAMPOS, 2003; CUNHA, 2005; OLIVEIRA, 2008), espraiando-se numa frutífera discussão sobre o cuidado e a produção de saúde na Atenção Básica à Saúde e na rede de serviços do SUS.

Atualmente, ela toma centralidade nos programas oficiais de qualificação da assistência à saúde, em especial na Política Nacional de Humanização do Ministério da Saúde, extrapolando da Atenção Básica para toda a rede do SUS, nos diversos níveis de complexidade, e fortalecendo a ideia de Rede de Atenção. Foca sua intervenção nas relações entre os diversos atores envolvidos no cuidado, os diversos profissionais, os usuários, os vários serviços, os vários setores, o território (BRASIL, 2007).

Nesta última perspectiva, assume importância a ideia da formação das equipes de referência para determinados grupos de usuários, superando o caráter fragmentado e anônimo do cuidado, e possibilitando ao usuário participar do seu próprio cuidado e se localizar durante seu percurso nos diferentes serviços da rede.

Essa perspectiva fortalece também a ideia da circulação dos saberes e do apoio matricial (CAMPOS, 1999), propondo um novo envolvimento e corresponsabilização das equipes, potencializando e tornando criativas as suas açôes, e potencializando o saber dos próprios usuários e da comunidade. Centrado no trabalho coletivo e em equipe, propóe por fim mudanças nas relações de poder que envolvem o funcionamento das relaçóes terapeuta-paciente, nas relaçôes entre os diversos atores e as instituiçóes, reivindicando um novo lugar para a gestáo do cuidado e das redes de serviços, que tende não apenas a trocar a verticalidade das relaçôes de hierarquia pela horizontalidade das relaçôes de cooperação, como a superar as divisóes estanques que separam o papel administrativo da função técnica, a produção da prática e do conhecimento dos procedimentos burocráticos, a prática da assistência de sua dimensão política.

Como se vê, as atuais discussóes em torno da mudança das práticas de saúde coletiva caminham em direção ao enriquecimento das possibilidades de ação e de transformação dos vários atores envolvidos no cotidiano dos serviços e da produção de saúde, e representa um avanço significativo na construção 
do SUS, pois, de fato, foca a questão da atenção à saúde nos atores reais nela envolvidos, superando as visôes gerenciais que separam de forma estanque as funçóes e os momentos do processo. Essas visóes gerenciais estanques que são questionadas pelas mudanças nas práticas de saúde coletiva dividem em diferentes tempos e entre diferentes atores as funçóes de planejar, executar e avaliar, e fortalecem a estrita e artificial separação entre os processos de prevenção, tratamento e reabilitação.

$\mathrm{O}$ processo de enriquecimento da prática tem utilizado o termo Clínica Ampliada para designar o âmago do processo de cuidar, o grande arcabouço de conhecimentos, práticas, posturas e relaçôes políticas envolvidas nas mudanças (CAMPOS, 2003). O termo Clínica Ampliada sugere a necessidade de integrar ao entendimento do processo saúde-doença as diversas dimensôes implicadas aos fenômenos do adoecimento e do sofrimento, acenando à necessidade de se ampliar o arco de respostas e de recursos, de forma a construir respostas complexas para perguntas complexas. Vários âmbitos relacionados à produçáo do sofrimento e da doença passam assim a ter um lugar e uma importância no estabelecimento das estratégias dos serviços e das equipes.

A ideia de Clínica Ampliada vincula-se e explica a proposta de construção de projetos terapêuticos singulares, ao invés de açóes individualizadas e fragmentadas entre as diferentes profissóes que constituem o arsenal tradicional da área da saúde. Os projetos terapêuticos aparecem aqui como o conjunto de estratégias estabelecidas pelas equipes, através de discussões, avaliações diagnósticas e levantamento de recursos e possibilidades (BRASIL, 2007). Esse conjunto de estratégias é formulado de forma a compor um conjunto de etapas que vão do diagnóstico à ação propriamente dita, e à avaliação da própria ação, considerando que, durante o percurso terapêutico, novas demandas surgem, novos caminhos se abrem, novas estratégias e intervençôes se fazem necessárias.

\section{Arcabouços teóricos e visões de mundo que sustentam as concepções de projetos Terapêuticos}

As mudanças de paradigma nas propostas de cuidado envolvem mudanças nos fluxos de poder e mutaçóes no campo do saber, o que não tem ocorrido sem resistências e dificuldades. Os modelos biomédicos de inspiração Flexneriana resistem ao processo de mestiçagem entre os vários campos do saber, e há tensóes entre paradigmas diferentes, numa luta por legitimidade. Muitos desses paradigmas, consubstanciados por arcabouços teóricos que envolvem concepções de cunho psicológico ou sociológico, nessa luta por legitimidade, não superam totalmente o risco de simplificar algo complexo como o processo saúde-doença e a questão do cuidado, tomando o lugar da perspectiva biomédica tradicional. O grande desafio é desenvolver uma leitura dos processos relacionais que não seja mecânica e doutrinária, em que a multiplicidade de discursos e a complexidade dos fenômenos possam ser tratados de forma dialógica, induzindo a produção de novas e inéditas concepçóes. De qualquer forma, e apesar dessas novas construçóes, o paradigma biomédico persiste, e muitas vezes os próprios atores que questionam esse paradigma demandam intervençóes nele pautadas.

Considerando a importância e o avanço que essa ideia de projeto terapêutico traz para o enriquecimento da prática, problematizo a seguir algumas dimensóes relativas à forma como se tem operado essas noçóes na prática do cuidado, a partir das experiências que vivi como supervisor clínico-institucional de alguns CAPS. Entendo que existe uma diversidade muito grande no que concerne à concepção de clínica e que a ideia de projeto terapêutico como arsenal de procedimentos, e não como construçáo de projetos de vida, está muito presente em algumas das práticas cotidianas que pude acompanhar.

Nos serviços territoriais e comunitários de saúde mental, como os CAPS, a discussão sobre a necessidade de se estabelecer projetos terapêuticos se faz muito presente.

Parece já haver uma cultura e um consenso em torno da necessidade de acompanhamento contínuo dos usuários, e as ideias de território, de trabalho intersetorial, de trabalho em rede, e de ação interdisciplinar apresentam-se bastante disseminadas (BRASIL, 2004, 2005), embora haja também diversas formas de compreendê-las e praticá-las. Assim como a noção de projeto terapêutico, a proposta de se estabelecer profissionais de referência para tecer e acompanhar tais projetos também é uma discussão presente em certos CAPS, representando uma tentativa de escapar à fragmentação das disciplinas e das intervençôes que dividem o usuário em fatias, respondendo mais às demandas de exercício do poder e de prestígio social das diversas profissóes do que as necessidades dos usuários.

As noçôes de projetos terapêuticos vigentes estão à linha de múltiplos pressupostos e formas de conceber a experiência do sofrimento psíquico e o cuidado. Há formas que ainda sustentam a ideia de 
causalidade linear (seja esta biológica, psicológica ou social) do fenômeno do sofrimento, e há formas que praticam uma ruptura com a linearidade, valorizando a descoberta e a experimentação.

A perspectiva linear e mecanicista vincula-se a uma concepção de tratamento, de melhora ou de cura essencialmente associada à eliminação de sintomas, sejam estes considerados alteraçôes da sensopercepção, do pensamento, do humor ou da cognição. Este olhar diagnóstico é marcado por uma concepção de clínica como supressão da doença ou do sintoma (ROTELLI; DE LEONARDIS; MAURI, 1990).

Um olhar psicodinâmico também se faz presente (ROTELLI, 1990), através da elaboração de causalidades e possíveis percursos focados no desenvolvimento psíquico. A presença de uma multiplicidade de linhas produz tensôes, e estes conflitos tanto podem produzir uma riqueza e a multiplicidade de respostas como podem ser paralisantes, o que dependerá do funcionamento da própria equipe, seu estilo, seu talento ou sua capacidade para garantir a liberdade, o exercício da criatividade e de invençôes inéditas, assumindo os riscos inerentes a tal processo. É certo que a psicanálise e seus sucessivos movimentos de reforma e transformação contribuíram e contribuem para a cotidiana prática do cuidado nos serviços da reforma psiquiátrica, atravessando-a, mas o que se quer aqui alertar é para as posturas menos dialógicas e mais enrijecidas, que por vezes tentam fazer caber em seu escopo explicativo fenômenos complexos que não se deixam simplificar por nenhuma abordagem específica.

Outro olhar que entende o sofrimento apenas como resultado de um processo social de exclusão se coloca como alternativa às duas linhas anteriores, sem, contudo, garantir a produção de uma crítica aos próprios parâmetros e normas sociais (ROZEMBERG; MINAYO, 2001). Tais linhas entendem o usuário do serviço como vítima de um processo de fragmentação social e podem reafirmar a invalidação e a menoridade dos usuários, desenvolvendo um processo de normalização e adaptação. Centradas exclusivamente numa crítica à exclusão e na afirmação de um projeto societário marcado pela centralidade do trabalho, deixam de vislumbrar a existência de processos emancipatórios desvinculados da sociabilidade da mercadoria e do trabalho, e associados a novas formas de se viver a vida (KURZ, 1999).

Uma ruptura epistemológica que transforme o objeto da saúde mental, no sentido apontado por Rotelli (1990) quando propóe ser este a'existênciasofrimento em sua relação com o corpo social', parece permanecer como um grande desafio. Isso exigiria da ciência lidar com a incerteza, ao admitir que pouco ainda conhecemos desse objeto complexo que é o sofrimento psíquico.

Tais formas hegemônicas de desenvolver a 'Clínica' ou, como preferimos, o cuidado correspondem, portanto, a determinados modelos de homem que foram forjados na modernidade, tomaram forma nos séculos XVIII e XIX, mas persistem até hoje, com nuances diferentes adaptadas aos valores e modos de vida da pós-modernidade.

As formas da sociedade de controle (DELEUZE, 1992) se cruzam com os modos de desregulamentação (BAUMAN, 2003), produzindo novas formas de controle, não apenas disciplinar, mas um controle associado a técnicas de abandono (KINKER, 2007).

Estas estratégias se pautam na produçáo de determinado tipo de homem que seja útil às formas atuais de produção e de movimentação da engrenagem do mercado, seja pela via do trabalho duro e penoso, seja através das vias sedutoras, mas náo menos invasoras e totalizadoras da vida, como a do chamado trabalho imaterial (NEGRI; LAZZARATO, 2001).

O conceito de homem da nascente psiquiatria biológica e das linhas psicodinâmicas é originário da época da industrialização e carrega consigo formas de conceber os modos de vida. Bauman (2003) lembra como as massas na época de Freud eram consideradas preguiçosas e pouco inteligentes, e como as técnicas psicanalíticas desenvolvidas junto à elite vienense haveriam de ser utilizadas apenas em alguns; para a grande maioria, o controle dos instintos deveria se dar por formas duras de vigilância, educação e correção. De qualquer forma, a concepção psicanalítica traz em seu bojo as marcas de um projeto civilizatório marcado pela sociabilidade moderna do trabalho.

Numa visão crítica à psicanálise, Deleuze e Guattari (2010) vão questionar a simplificação e o empobrecimento dessa visão de homem da psicanálise e sua correspondente forma de conceber o inconsciente, dizendo que este não é representativo, mas produtivo, múltiplo, produtor de vida. Para eles, a esquizofrenia dos doentes mentais é uma caricatura do potencial de desterritorialização do capitalismo. Outra esquizofrenia, contudo, seria produtora de subjetivação, superando a noção estanque de identidade e de eu.

Rotelli (1990, p. 97) vai também na direção de uma problematização das concepçôes que tentam descrever numa linha lógica e mecânica os mecanismos psíquicos, ao a firmar que 
Também o divã é uma instituição inventada, mas para um objeto todo interno à autonomia do psíquico, a uma singularidade psicológica simplificada primeiro e depois tornada infinitamente complexa (e por isso sedutora). Aqui a simplificação originária deixa dúvida o quanto procede e o higienismo do setting, como aquele ambulatorial, é não apenas um modo da prática mas é constitutivo da episteme psicanalítica.

Um dos riscos presentes na construção dos projetos terapêuticos desenvolvidos nos CAPS, em alguns casos, diz respeito à simplificação do objeto da saúde mental apontado acima, ou seja, ao entendimento deste como doença, ou reflexos de mecanismos psicológicos mecanicamente articulados, ou ainda como fruto de processos de exclusão das formas 'normais' de viver.

O risco dessa concepção é estabelecer uma série de estratégias que substituem as antigas e fragmentadas intervençóes disciplinares sem, contudo, modificar o entendimento e o olhar sobre o fenômeno. Seria como encontrar novos remédios para substituir os velhos, mas tratando dos mesmos objetos, buscando a cura, efetivando o tratamento da doença.

Um dos sinais de que esta armadilha pode estar próxima é a rigidez e o estabelecimento de normas rígidas de funcionamento da instituição, a repetição de repertórios de açóes e uma padronização das respostas por tipo de problemas. Esse tipo de aggiornamento ou modernização ou atualização (CASTEL, 1978) é um risco sempre constante, que pode conviver contraditoriamente com processos de transformação da prática, como que tentando boicotá-los ou torná-los inócuos, já que a repetição de repertórios e a segurança que trazem costumam ser armas contra as inseguras, sempre incipientes e instáveis, invençóes.

Essa troca de procedimentos, sem modificar o olhar sobre o fenômeno, pode fazer com que a contenção mecânica ou química como mecanismo de proteção da ordem institucional seja substituída por uma atividade recreativa ou uma oficina terapêutica; a invalidação da voz do usuário pode ser transferida do espaço escuro e abafado do manicômio para o grupo terapêutico ou de orientação (SARACENO, 1999).

Evidentemente que todas as atividades sugeridas são importantes e podem compor processos potentes de transformaçáo, se elas se dão em conexão com o contexto real e concreto de vida dos usuários, considerando suas relaçóes, os espaços que ocupam, os espaços que lhes são proibidos, seus desejos e planos para o presente e o futuro. Mas elas, desconectadas desta realidade, podem representar formas de controle, pois não guardam em si a potencialidade de transformar a experiência de vida e a forma como o usuário do serviço vive o seu sofrimento.

Afinal, os elementos em jogo durante essas intervençóes terapêuticas são múltiplos, ultrapassando significativamente a constituição da relação terapeuta-paciente. Fatores como os motivos da presença do usuário na unidade, as características de seu contexto de vida, o lugar social que ocupa, a organização e as relaçóes entre os atores da instituição, o que representa a instituição em seu território, e tantos outros, compóem esse quadro que é sintetizado e transmitido em forma hologramática no ato terapêutico, seja este individual ou grupal.

Parece que a riqueza de experiências e de trocas sociais é que guardam o germe da mudança, e elas muitas vezes solicitam um tipo de apoio que possibilite o experimentar; são mudanças nos contextos, possibilitadas por pequenas rupturas na ordem dos elementos em jogo (SARACENO, 1999), que podem abrir brechas para experiências inéditas de vida.

É como mudar determinada peça do jogo de xadrez, possibilitando uma mudança repentina das linhas de força. Mudanças nas cenas (ROTELLI, 1990). A superação de algumas divisóes se faz necessária para resgatar a complexidade do objeto de intervenção da saúde mental, de forma a se sobrepor às visóes de homem que simplificam e empobrecem a existência.

Pensar na superação da divisão cartesiana dos vários pares antagônicos tais como o de sujeito-objeto, corpo-alma, natureza-cultura (MORIN, 2001, 2002), nos leva a problematizar a divisão inconscienteconsciente, biológico-cultural, social-clínico.

\section{Projeto Terapêutico como produção de vida}

A possibilidade de enriquecer a existência, e enriquecer a saúde mental, passa pela superação dessas dissociaçôes fundamentais que fomos produzindo ao longo da história e nos levou à situação atual em que corremos o risco da destruição do planeta. É possível empreender um modo dialógico e complexo de conceber os sujeitos, que opere mais por conjunção e fermentação e supere as disjunçôes disciplinares fragmentadoras da experiência. Vários autores de diferentes correntes do pensamento, como Morin (1996), Deleuze e Guattari (2004), Serres (2003), Rotelli (1994), dentre outros, têm apontado nesse sentido. Esse modo complexo de conceber o homem, como um ser misturado à natureza que se modifica 
sem cessar, poderia pautar a construção dos projetos terapêuticos singulares.

A ideia do projeto terapêutico como um conjunto de procedimentos, desse ponto de vista, não pode responder integralmente ao desafio de se transformar a qualidade das relaçôes e de produzir vida, já que se mantém atrelada a uma visão simplificadora sobre a experiência do sofrimento.

As estratégias de intervenção são parte de uma construção, sem dúvida, mas elas não representam a totalidade do que seria um projeto terapêutico. Isso porque se reproduz nessa limitação do conceito a ideia de intervenção num objeto inerte, em busca de uma suposta normalidade.

O processo a ser construído em permanente diálogo com os usuários dos serviços e a multiplicidade de elementos em jogo no cotidiano é a bricolagem de um projeto/processo de vida (NICÁCIO, 2003), muito mais do que um conjunto administrativo, técnico, científico de procedimentos a serem aplicados nos usuários.

Dessa forma, o projeto terapêutico não cabe em formulários e registros de atendimento; ele é um processo dialógico e dinâmico cuja imensidão é inexprimível, não cabendo em fichas. Essas podem ajudar na organização do processo, mas náo representam o processo na sua totalidade.

$O$ projeto terapêutico às vezes pode ser entendido como aquele formulário ou ficha de registro que, além de possuir dados da história, contém as estratégias e os procedimentos da 'clínica', as prescriçóes da equipe e os contratos estabelecidos com os usuários, como as atividades a serem desenvolvidas, os dias de frequência na unidade, etc. Mas ele pode ser muito mais que isso.

A construção do projeto terapêutico como projeto de vida (NICÁCIO, 2003) implica a modificação permanente das cenas que geram o empobrecimento da existência (ROTELLI, 1990), diminuem a potência de agir (SPINOZA, 2009), limitam as experimentaçôes e os encontros entre os atores sociais.

A formulação do projeto terapêutico é, entâo, um movimento disperso no tempo, mas que marca espaços transformando-os em lugares com significado, como diz Saraceno (1999), ao discutir a questão do habitar na perspectivada reabilitação psicossocial.

O diálogo, a multiplicação dos atores envolvidos e das cenas experimentadas representam então o arcabouço de constituição dos projetos terapêuticos. A mudança das cenas que despontencializam e a construção de novas cenas estão relacionadas à construçáo de novas práticas, novos saberes, novos valores, ou seja, compreendem essencialmente modificaçóes nos fluxos de poder, mudanças micropolíticas e microfísicas (no sentido da microfísica de poder de Foucault), metamorfoses dos papéis, das formas de conceber o sofrimento e viver a vida (FOUCAULT, 2008).

O termo projeto pode ser problemático por remeter a algo como um plano pré-estabelecido que deve ser seguido à risca, sem desvios. Mas podemos entender também o termo projeto como um apontar caminhos ao caminhar (NICACIO, 2003), como o próprio caminhar que mistura o desenho de um mapa às contingências da vida (como o navegar no navio num oceano incerto, que exige o talento do piloto de imprimir movimento sendo, ao mesmo tempo, impelido por movimentos exteriores) (SERRES, 2008).

O projetar pode se situar na linha do que o saudoso sanitarista David Capistrano Filho (1995) chamava de fazejamento, quando discutia a necessidade de rever a rígida divisão entre teoria e prática, planejamento, execução e avaliação, no caso da implantação das políticas de saúde.

O projeto então seria a viagem com os usuários dos serviços pelos territórios existenciais (GUATTARI, 1990), sempre em companhia de todos os elementos que ajudam a compor a cena, e que estáo permanentemente presentes com suas linhas de força modelando o perfil de qualquer relação terapêutica, ou mesmo de qualquer diálogo entre terapeuta-paciente que se dê em qualquer lugar.

O projeto terapêutico é o processo de transformação a que todos os atores implicados estão sujeitos, sejam eles usuários, seus familiares, profissionais, outros personagens presentes na vida dos sujeitos. Ele será mais ou menos terapêutico a depender das transformaçôes em curso, modificando as cenas, pois a mudança do usuário depende da mudança do profissional do serviço e dos atores sociais envolvidos na vida concreta e substancial dos usuários (KINKER, 2012).

O projeto terapêutico tem então uma dimensão singular e outra coletiva, lembrando que essas dimensôes compóem um todo indissociável, que compõem as cenas, até porque as pessoas são compostas por multiplicidades, por sociedades inteiras. O projeto terapêutico singular dialoga com o projeto institucional dos serviços, esteja este explicitamente esboçado por seus atores ou simplesmente vivido por eles sem muita crítica.

A vida comum cotidiana das instituiçóes coproduz tanto o sofrimento como a intensificação da vida dos usuários, o projeto da instituição intervém sobre o projeto terapêutico singular dos usuários, ou como uma leve onda que vem lamber a areia do 
mar ou como a onda poderosa que náo deixa pedra sobre pedra.

A possibilidade de a instituição entrar em crise é a porta de entrada para a produção de vida junto aos usuários (ROTELLI, 1990).

\section{Conclusão}

Em sintonia com as transformaçóes ocorridas nas últimas décadas no campo da reforma psiquiátrica e da reforma sanitária, a ideia dos projetos terapêuticos singulares ou individuais tem ocupado um importante lugar na prática do cuidado.

A produção do cuidado e a noçáo de terapêutico se originam de campos discursivos próprios (FOUCAULT, 1972) que produzem determinadas realidades, nas quais os conceitos de saúde, de vida e de normalidade estão presentes. Modelos de homem e de vida marcados por paradigmas biológicos, psicológicos e sociais têm influenciado a construção dos projetos terapêuticos e do que se convencionou chamar de clínica ou de cuidado.

Este artigo trouxe inicialmente um olhar crítico sobre tais modelos e paradigmas, argumentando que a experiência do sofrimento psíquico é de tal forma complexa que as explicaçóes mecânicas e lineares não conseguem dialogar com ela de forma a produzir metamorfoses nas cenas que reproduzem a invalidação e a ausência de sentido.

Associada a esses olhares supostamente reducionistas, que defendem determinado funcionamento natural do corpo, do psíquico e do social, o projeto terapêutico pode surgir como uma simples ferramenta que expressa a operacionalidade dos agentes de saúde sobre um objeto inerte, sem vida, ou comum à vida que desvia dos padróes normais e esperados de funcionamento. Processos de normalização e adaptação podem surgir desses mecanismos de tratamento que projetam para o futuro a construçáo de um determinado tipo de homem.

O desafio torna-se, então, estabelecer um diálogo múltiplo e rico no processo de cuidado, entendendo como projeto terapêutico aquele fazer e tecer a vida junto aos usuários dos serviços, em seus cotidianos concretos de vida e de relaçôes, modificando as cenas que geram a violência e a invalidação e transformando assim todos os atores envolvidos: os usuários, os profissionais e a própria sociedade.

Tal projeto terapêutico, por sua imensidáo e potência, é inexprimível, não cabendo em simples formulários, prescriçôes e registros das instituiçôes. Esse fluir de transformaçóes pode se utilizar, contudo, de mecanismos de registro-memória, projetualidades que se transformam ao caminhar num processo coletivo de metamorfose.

O projeto terapêutico, nessa perspectiva, é muito mais que um conjunto de estratégias e procedimentos estabelecidos pelas equipes de cuidado e pelas instituiçóes. Ele é o próprio fazer junto aos usuários. Ele não se confunde com o conjunto de procedimentos que as unidades de saúde oferecem aos usuários, embora possam fazer uso disso. Mas eles representarão muito mais formas de controle dos desvios e de dominação se subjugarem toda a incandescência da vida e das relaçóes a um processo prescritivo com objetivos terapêuticos, se eles não entenderem que a vida concreta nos territórios de existência é que compóem a complexidade do viver e do sofrimento, sendo um arcabouço espetacular de possibilidades de transformação.

Quando o diálogo com os usuários dos serviços nos levar à conclusão de que as cenas e os contextos é que precisam ser transformados, levando à transformação de todos nós, aí então o termo projeto terapêutico poderá assumir plenamente outro lugar nas práticas de cuidado, contribuindo para a produção de novas formas enriquecedoras de sociabilidade.

\section{Referências}

BAUMAN, Z. Comunidade: a busca por segurança no mundo atual. Rio de Janeiro: Zahar, 2003

BRASIL. Ministério da Saúde. Secretaria de Atenção à Saúde. Coordenação Geral de Saúde Mental. Reforma psiquiátrica e política de saúde mental no Brasil. Documento apresentado à Conferência Regional de Reforma dos Serviços de Saúde Mental: 15 anos depois de Caracas. Brasília: Ministério da Saúde, 2005.

BRASIL. Ministério da Saúde. Secretaria de Atenção à Saúde. Departamento de Açôes Programáticas Estratégicas. Saúde mental no SUS: os centros de atençáo psicossocial. Brasília: Ministério da Saúde, 2004.

BRASIL. Ministério da Saúde. Secretaria de Atençáo à Saúde. Núcleo Técnico da Política Nacional de Humanização. Clínica ampliada, equipe de referência e projeto terapêutico singular. Brasília: Ministério da Saúde, 2007.

CAMPOS, G. W. S. Equipes de referência e apoio especializado matricial: uma proposta de reorganização do trabalho em saúde. Revista Ciência e Saúde Coletiva, Rio de Janeiro, v. 4, n. 2, p. 393-404, 1999.

CAMPOS, G. W. S. Saúde paidéia. São Paulo: Hucitec, 2003.

CAPISTRANO FILHO, D. Da saúde e das cidades. São Paulo: Hucutec, 1995.

CASTEL, R. A ordem psiquiátrica: a idade de ouro do alienismo. Rio de Janeiro: Graal, 1978. 
CUNHA, G. T. A Construção da Clínica Ampliada na Atenção Básica. São Paulo: Hucitec, 2005.

DELEUZE, G. Conversaçôes. São Paulo: Editora 34, 1992.

DELEUZE, G.; GUATTARI, F. Mil platôs: capitalismo e esquizofrenia. São Paulo: Editora 34, 2004.

DELEUZE, G.; GUATTARI, F. $O$ anti-Édipo: capitalismo e esquizofrenia. São Paulo: Editora 34, 2010.

FOUCAULT, M. A arqueologia do saber. Petrópolis: Vozes, 1972.

FOUCAULT, M. Microfisica do poder. Rio de Janeiro: Graal, 2008.

GUATTARI, F. As três ecologias. Campinas: Papirus, 1990.

KINKER, F. S. Encontro terapêutico ou processometamorfose: desafio dos serviços territoriais e comunitários. Saúde em Debate, Rio de Janeiro, v. 36, n. 95, p. 695-701, 2012.

KINKER, F. S. O lugar do manicômio: relato da experiência de desconstrução de um hospital psiquiátrico no interior do Nordeste. 2007. 173 f. Dissertação (Mestrado em Ciências Sociais) - Pontifícia Universidade Católica de São Paulo, São Paulo, 2007.

KINOSHITA, R. T. Em busca da cidadania: desinstitucionalização de um hospital psiquiátrico. In: BRAGA CAMPOS, F. C.; HENRIQUES, C. M. P. (Org.). Contra a maré à beira-mar: a experiência do SUS em Santos. São Paulo: Scritta, 1996. p. 39-49.

KURZ, R. Antieconomia e antipolitica: sobre a reformulação da emancipação social após o fim do marxismo. São Paulo: USP, 1999. Mimeografado.

MORIN, E. A noção de sujeito. In: SCHNITMAN, D. F. (Org.). Novos paradigmas, cultura e subjetividade. Porto Alegre: Artes Médicas, 1996. p. 45-58.

MORIN, E. O método 4: as ideias, hábitat, vida, costumes, organização. Porto Alegre: Sulina, 2002.

MORIN, E. Os desafios da complexidade. In: MORIN, E. A religação dos saberes: jornadas temáticas idealizadas e dirigidas por Edgard Morin. Rio de Janeiro: Bertrand Brasil, 2001. p. 559-567.

NEGRI, A.; LAZZARATO, M. Trabalho imaterial: formas de vida e produção de subjetividade. Rio de Janeiro: DP \& A, 2001

NICÁCIO, M. F. S. O processo de transformação da Saúde Mental em Santos: desconstrução de saberes, instituições e cultura. 1994. 155 f. Dissertação (Mestrado em Ciências Sociais) - Pontifícia Universidade Católica de São Paulo, São Paulo, 1994.

NICÁCIO, M. F. S. Utopia da realidade: contribuiçóes da desinstitucionalização para a invenção de serviços de saúde mental. 2003. 224 f. Tese (Doutorado em Saúde Coletiva) - Universidade Estadual de Campinas, Campinas, 2003.

OLIVEIRA, G. N. O projeto terapêutico e a mudança nos modos de produzir saúde. São Paulo: Hucitec, 2008.

ROTELLI, F. A instituição inventada. In: NICÁCIO, M. F. S. (Org.). Desinstitucionalização. São Paulo: Hucitec, 1990. p. 89-100.

ROTELLI, F. Modelli scientifici e complessità. In: ROTELLI, F. Per la normalità: taccuino di uno psichiatria: scritti 1967-1993. Milano: Edizione E, 1994. p. 58-63.

ROTELLI, F; DE LEONARDIS, O.; MAURI, D. Desinstitucionalização, uma outra via: a reforma psiquiátrica italiana no contexto da Europa Ocidental e dos "Países Avançados”. In: NICÁCIO, M. F. S. (Org.). Desinstitucionalização. São Paulo: Hucitec, 1990. p. 17-59.

ROZEMBERG, B.; MINAYO, M. C. S. A experiência complexa e os olhares reducionistas. Revista Ciência e Saúde Coletiva, Rio de Janeiro, v. 6 n. 1, p. 115-123, 2001.

SARACENO, B. Libertando identidades: da reabilitação psicossocial à cidadania possível. Belo Horizonte: Te Corá/Instituto Franco Basaglia, 1999.

SERRES, M. Hominescências: o começo de uma outra humanidade. Rio De Janeiro: Bertrand Brasil, 2003.

SERRES, M. Ramos. Rio de Janeiro: Bertrand Brasil, 2008.

SPINOZA, B. Ética. Belo Horizonte: Autêntica, 2009. 